\title{
¿TIENE EL HOMO OECONOMICUS SENTIDO DEL DEBER?
}

\author{
Jesús ZAMORA BONILLA \\ UNED
}

ABSTRACT: I invite readers to read this paper on 'Kantian ethics', 'economic rationality', the 'sense of duty', 'categorical imperatives', and so on, and answer whether they think it should have an abstract at all.

Era ya tarde en la fría noche de la gran ciudad. Volvía a casa, cuando de pronto vi luz en un bar. No lo dudé: hacía un frío del demonio, así que en él entré. Casi nada más acercarme a la barra, empecé a arrepentirme de mi decisión (precipitada, como casi todas), pues el tugurio recogía a aquellas horas intempestivas a una caterva de individuos con los que en modo alguno me gustaría salir de nuevo a mi solitario y mal iluminado camino. Daba la impresión de que aquella cuadrilla de bribones (quienes, por otro lado, conversaban bien poco, o nada, entre sí, intercambiando sólo alguna que otra mirada de las que hielan el aliento) sólo mantenía una frágil apariencia de orden público debido a la presencia formidable de un mesonero enorme, tirando a gordo, con el pelo rapado al cero coma cinco, quien exponía con los brazos cruzados unos tatuados bíceps cuyo perímetro fácilmente superaría al de mis propios muslos, y que, sin fijar los ojos como quien dice en ningún sitio en particular, parecía controlar hasta el menor murmullo de la concurrencia.

- ¿Qué ponemos? - me sorprendió su voz, que no dejaba de traslucir un cierto deje de extranjero, mientras yo hacía un tímido examen a los posibles asesinos dispuestos a sacarme la faca en cuanto me hubiera alejado dos pasos en la oscura noche, si es que no alli mismo, a la vista de todos.

-Eh..., un carajillo muy caliente, por favor.

El mesonero dio media vuelta muy despacio hacia la máquina del café, sin cambiar su expresión amenazante que se diría de serie, y al poco volvió con un pequeño vaso de cristal humeante, lleno hasta arriba de un mejunje que, aun si 
aparentaba ignorar cuál pudiera ser el significado de los conceptos de calidad e higiene, contenía una mezcla tan fuerte de cafeína y de alcohol puro, entre quizás otras sustancias de más difícil verificación, que en seguida me hizo ir sintiéndome un poco más confiado a la vez que menos aterido de frío. Al tercer o cuarto traguito de aquella pócima, que atravesaba mi tubo digestivo con la potencia de un misil, me volvió a sorprender la voz de la musculosa esfinge, quien, sin dirigirme la mirada, y pronunciando muy marcadamente las erres, me dijo:

- No sé qué pasarrá esta noche, perro es usted el segundo que me pide las cosas porr favorr -e hizo un giro casi imperceptible con la cabeza, para mostrarme la figura de un hombrecillo de edad más o menos avanzada, sentado en una mesa al fondo del bar, casi de espaldas a nosotros, y que parecía absorto en la lectura de un libro, no sabía entonces si por el interés de su contenido, o por fingir, como intentaba yo, no darse cuenta de las compañías.

- ¿Tampoco es aquél un parroquiano habitual? - pregunté al tabernero, quien sólo contestó ladeando unos milímetros la cabeza y torciendo los labios en una mueca de indiferencia hacia las novedades. Atraído por la presencia de una persona medianamente normal (aunque en seguida llegaría a la conclusión de que normales, lo que se dice normales, debían de serlo mucho más los otros granujas que decoraban el establecimiento), agarré el medio carajillo que me quedaba y fui hacia la mesa del inaudito lector. El libro que tenía entre las manos era viejo, pequeño, y estaba forrado con las coloridas hojas de alguna revista; entre las últimas páginas asomaba el pico de un billete de metro que estaría siendo usado como separador. Tosí ligeramente.

-Buenas noches, ¿le importa que compartamos la mesa? - y añadí muy bajito- Entre nosotros, el resto de la clientela parece menos recomendable, y todas las mesas están ocupadas.

El hombre levantó la mirada hacia mí, como examinándome muy brevemente, y mientras lo hacía sentí que lo había conocido mucho antes. No dudé en preguntárselo en cuanto me autorizó a sentarme junto a él, y de nuevo fue la mía tal vez una decisión demasiado precipitada.

- No sé. A mí usted no me suena de nada, con perdón. Yo me llamo Juan López Pérez, para servirle - dijo, mientras me indicaba la silla que había enfrente de él; su nombre era tan revelador para mí como uno cualquiera sacado al azar de la guía de teléfonos. 
-Quizá nos hemos visto por la universidad, o en algún congreso; yo soy profesor, sabe usted - $y$ mientras me sentaba le dije mi nombre y algunos otros datos del pedigrí con el que solemos presentarnos unos a otros los miembros de la tribu académica.

-Ah, caramba. Entonces, tal vez. Pero, a pesar de lo talludito que usted me ve, yo estoy en la universidad sólo como alumno, y desde hace muy poco. El año pasado me matriculé en Filosofía, pero demonios, reconozco que a veces es más difícil de lo que pensaba, y a mis años uno ya no tiene la agilidad mental de antes. Además, estudio a distancia y veo poco a los profesores.

-Puede que nos conozcamos de alguna otra cosa. Insisto en que me resulta usted muy familiar, y mucho más cuanto más le escucho. ¿Le puedo preguntar en qué trabaja?

Demoró su respuesta por unos instantes que se me hicieron larguísimos, como si le costase dar esa información a un completo desconocido. Al final, con la vista fija en el libro cerrado, que, descansando sobre la mesa, se veía cubierto con fotos de alguna cuasiadolescente cantante de moda, dijo muy poco a poco:

-Ahora no soy más que un ocioso jubilado, pero cuando estaba en activo, fui el homo oeconomicus - y al pronunciar esas palabras me miró por fin. Entonces fui yo quien guardó silencio, abrumado por la sorpresa; sólo algún que otro sorbo que le iba dando al carajillo ponía de manifiesto que no me había convertido en una estatua en ese mismo instante. La mayoría de la gente habría tomado aquella declaración como una simple cuchufleta, pero yo percibí de inmediato las razones por las que aquel hombrecillo me estaba resultando tan familiar desde el principio... ¡Había estado estudiándolo durante años y años, y ahora lo tenía frente a mí, en el lugar más inverosímil que podría ocurrírseme! Era como si Darwin se hubiera encontrado en el jardín de su casa con un Australopitecus parlante, o aún más extraño, como si Arquímedes y Pitágoras hubieran coincidido en un viaje por mar con un principio y un teorema que también fuesen pasajeros de la misma nave. No sabía qué decir. Al cabo, un poco a lo loco, de mi boca salió un comentario más bien estúpido. Para mi desgracia, no fue el último de ellos que haría esa noche:

—Perdone, pero siempre había creído que era usted un tipo ideal. 
Juan López abrió las manos y se miró despaciosamente.

- Tampoco estoy tan mal para mi edad, aunque en mis ańos mozos era mucho más digno de ver. Y en cuanto a mis otras cualidades... en fin, debe haberlos peores —el comentario me descolocó más todavía.

-No, no, disculpe - repliqué aturdido-. Lo que quiero decir es que pensé que el homo oeconomicus no era más que una personalidad ficticia, una hipótesis abstracta que los economistas introducen en algunas de sus teorías.

-Ah, eso sí que no. A lo largo de mi vida me he hartado de ir de aquí para allá, a que quienes querían hablar de mí me hicieran más y más preguntas... Como para decirme ahora que no soy una persona de carne y hueso. Aunque, para que se quede usted más tranquilo, debe saber que mucha gente ha tenido la misma reacción cuando hemos sido presentados.

Supongo que a uno siempre se le queda una expresión de estúpido integral cuando se encuentra con alguien así, un personaje soñado al que durante toda tu vida habrías querido exprimir con cientos de preguntas (si hubieras pensado que aquello era posible, naturalmente). Y supongo también que en todos esos casos la expresión es del todo verídica, pues la memoria se te vacía, la inteligencia se te encasquilla, la lengua se apelmaza, y quedas sin forma alguna de reaccionar, como no sea haciendo alguna estupidez. La mía fue preguntar por el libro que mi interlocutor estaba leyendo. En vez de responderme, me lo acercó. Mi sorpresa fue de nuevo mayúscula: era la Fundamentación de la metafisica de las costumbres, en una vieja edición de Espasa-Calpe, muy sobada, desencuadernada por algunos lugares, y con anotaciones que parecían antiguas, y a las que me referí por hablar de algo.

-No las he escrito yo —aclaró Juan —, el libro es de segunda mano; ya sabe, hay que ser ahorrativo - aunque no pareció que esto último lo dijera en tono de disculpa. Al cabo de un instante, al ver que yo no añadía nada, tomó él de nuevo el curso de la conversación:

"Tengo un examen de Ética dentro de un par de semanas, y, a decir verdad, el bueno de Kant se me está atragantando más de lo que pensaba. Aristóteles, Epicuro y Hume me han parecido espléndidos, claros como la luz del día (en general), y, sobre todo, muy convincentes... pero Kant, reconozco que en 
muchos sitios me cuesta trabajo llegar a entender simplemente qué es lo que me quiere decir. Quizá, siendo usted del gremio de los filósofos, podría echarme una mano y explicarme algunas cosas... - yo seguía con la vista fija en el libro y asintiendo estúpidamente con la cabeza, como esos perros de plástico que coloca la gente en los coches, y sin enterarme demasiado de lo que Juan decía; lo tomó por un sí, y ¡vaya!, creo que fue mi única decisión afortunada de la noche, la única que yo no tomé-. ¡Oh!, le estaré sumamente agradecido - dijo-. Si me permite el libro... mire, mire, aquí, por ejemplo (tengo marcada la página, es justo lo que estaba leyendo por enésima vez cuando usted vino), donde dice "la voluntad es pensada como una facultad de determinarse uno a si mismo a obrar conforme a la representación de ciertas leyes. Semejante facultad, sólo en los seres racionales puede hallarse, y bla, bla, blan. En fin, creo que eso no se parece nada a lo que yo entendería por "voluntad racional» si me pidieran una definición - ¿me estaría sugiriendo que se la pidiera?; yo seguía con mis automáticos y perrunos gestos de asentimiento, lo cual debió de parecerle bastante-. Claro, cómo no. Pues verá, racional es aquel individuo que toma siempre las decisiones que, de acuerdo con la información que posee, son más coherentes con sus preferencias, ¡ni más ni menos! Y no veo qué tenga esto que ver con lo de... — - volvió a buscar entre las páginas amarillentas- "obrar conforme a la representación de ciertas leyes». ¿Qué le parece a usted?

Para poder asimilar la pregunta y empezar a pensar alguna respuesta coherente necesitaba el último sorbo de mi carajillo... por lo menos. Me quedaba tan poco en el vaso que no tuvo ningún efecto apreciable, así que miré hacia la barra del bar, con cierto apuro, y le indiqué por señas al coloso escanciador que me sirviera otro. Aún con el vaso levantado con una mano, y apuntándolo con el índice de la otra, me volví hacia Juan López y le pregunté si quería algo. Pidió un cortado. Me demoré reformulando la cuestión en voz alta hasta que nos sirvieron las consumiciones y tomé, de un solo trago, la mitad de la mía.

-Bueno — dije al fin-, yo creo que sí que existe una relación muy importante -mi tono de voz había subido, estimulada por el ignoto contenido del carajillo; debió sonar tan extraña en aquel tugurio que, para aumento de mi congoja, varias miradas se posaron en mí de la misma manera que lo habrían hecho sobre una cucaracha marciana; hablé entonces un poco más bajo-. Para empezar, Kant afirma que todos los seres están sometidos a leyes, pero que hay dos formas en las que puede darse este sometimiento: por un lado, los seres naturales (es decir, los "fenómenos") se comportan necesariamente según ciertas leyes 
o regularidades, aunque cuáles sean estas regularidades tendremos que encontrarlo empíricamente; por otro lado, nosotros, como seres racionales, tenemos la capacidad de actuar según lo que pensamos que debemos hacer. Es decir, concebimos una regla que dice que "en estas circunstancias, lo que se debe hacer es

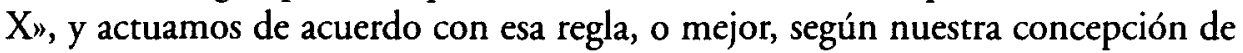
la regla. Seguramente, en lo que no estará usted de acuerdo con Kant es más bien en qué regla es aquella a la que nuestras acciones están sujetas.

-Efectivamente, tengo mis más y mis menos sobre esa cuestión. Pero antes de discutirla permítame insistir: en mi opinión, lo que hace mi voluntad es decidirse en cada caso por aquella alternativa que me parece más satisfactoria, pero yo no tomo esa decisión a causa de mi "representación" del principio que dice que "debo" hacerlo; más bien sólo me doy cuenta de que sigo esa "regla" cuando reflexiono conscientemente sobre ello, si acaso. Por tanto, no es la «representación" de la regla la que me determina a seguirla en la mayoría de las ocasiones.

-Pero sí que hay otros pensamientos que "conducen" a su decisión, ¿no? Al fin y al cabo, uno no toma las decisiones «acertadas" simplemente por instinto, como si le "salieran" así sin saber por qué, igual que los granos: lo que nos permite llamarnos racionales es que nuestras decisiones sean el resultado de un razonamiento, de una cadena de inferencias, o algo así. $\mathrm{Y}$ algunos pasos de esos razonamientos tienen, al fin y al cabo, una estructura como «en tales y cuales circunstancias, si deseo alcanzar tales y cuales cosas, debo hacer tal y cual». Ese tipo de "principios» (al menos en el sentido de esquemas generales de inferencia) sí que nos mueven a actuar, y no pueden "mover" así más que a seres racionales.

- ¿Y qué me dice — sonrió Juan — de los animales que parecen tomar decisiones complicadas pero muy juiciosas, vistas desde fuera? Algunos experimentos muestran que muchos pueden incluso responder a las modificaciones de sus incentivos de forma bastante coherente con la teoría de la decisión racional, sin que ellos tengan la necesidad de llevar a cabo razonamientos verbales.

- Hombre, está claro, después de Darwin, que la diferencia entre seres racionales e irracionales no puede marcarse de modo tajante: al fin y al cabo, debe de haber habido seres, en nuestra línea evolutiva, "menos racionales" que los humanos pero «más racionales» que los peces. Esto significa sencillamente que la capacidad de hacer inferencias no es sólo una capacidad "verbal", sino que puede estar encarnada en la propia actividad de un ser. Pero lo importante es que nuestra capacidad de verbalizar esas inferencias, de representarnos conscientemente las reglas 
por las que se van guiando nuestras decisiones, nos abre un abanico de opciones con el que otros animales no pueden ni siquiera soñar, en parte porque esa capacidad nos permite descubrir muchas más de tales reglas (normas prácticas del tipo «si pasa tal, haz cual», o "si pasa esto, también puede pasar aquello... o no pasar»), y en parte porque nos permite combinarlas unas con otras en cadenas de razonamiento muy complicadas. Así que, esa frase de Kant que usted me decía creo que sencillamente enuncia el hecho de que las acciones de los "seres racionales" son por lo general el resultado del «raciocinio».

-Un raciocinio espléndido el suyo, si me permite decirlo. Pongamos que me ha convencido - aquel halago contribuyó, con no poca ayuda del segundo carajillo, a ir transformando mi primera turbación en un cierto entusiasmo: ¡nada menos que el mismísimo homo oeconomicus me daba la razón en una discusión sobre el concepto de racionalidad! Era una pena que el mesonero no expidiese allí mismo certificados que poder presentar en las solicitudes de sexenios. Mi entusiasmo, empero, no había de durar mucho-. Claro que - siguió diciendo Juan - esa era sólo una de mis muchas dificultades (y no crea que la tomo como definitivamente resuelta; por ejemplo, aún tengo la duda de si Kant aceptaría que la voluntad racional puede determinarse a obrar por la representación de ciertas leyes falsas, o al menos, no objetivamente válidas; por lo que usted ha dicho, parece que lo importante es sólo que uno crea dichas leyes, y no sé si eso es muy kantiano; pero esa parte de la filosofía de Kant la tengo todavía más verde así que, como le digo, le admitiré su posición).

"Hay también otros conceptos - siguió- que me cuesta trabajo entender. ¿Qué me dice de la frase siguiente? - pasó varias páginas hasta dar con ella-: "una acción hecha por deber tiene su valor moral, no en el propósito que por medio de ella se quiere alcanzar, sino en la máxima por la cual ha sido resuelta; ella depende (aquí me salto un trozo) del principio del querer según el cual ha sucedido la acción, prescindiendo de todos los objetos de la facultad de deseam. Reconozco que, por más que me estrujo los sesos, no llego a comprender exactamente qué demonios entiende Kant por una "máxima", o como también dice, un "principio del querer». Aunque le pueda parecer extraño, tampoco tengo muy claro, para empezar, lo que podemos entender por «deber». Pero vamos a lo primero: ¿qué piensa usted que es una "máxima"? ¿Sería lo mismo que lo que acaba de mencionar cuando hablaba de las "normas prácticas» que intervienen en nuestros razonamientos? 
"Dios mío", pensé, "cómo voy a contestar a esto con lo poco que queda de mi carajillo». No me atreví, de todas formas, a pedir uno más... todavía.

-Puessss... no, no exactamente. O mejor dicho, sólo en parte. Las máximas deberían ser las reglas del más alto nivel... No sé si me... En fin, quiero decir que, cuando razonamos, intentamos llegar a nuestra decisión realizando inferencias que están basadas en reglas implícitas del tipo "si tal, entonces cual", por ejemplo, "si llueve, cogeré el paraguas"; pero cada una de esas reglas debe poder ser ella misma la conclusión de un razonamiento, es decir, puedo preguntarme "ipor qué tengo que coger el paraguas si llueve?", y las razones deben ser del mismo tipo, pero más generales: "porque, si me mojo, estaré muy incómodo y puedo enfermar». "¿Y por qué debo evitar estar incómodo?», podemos seguir preguntando...

-Sí, me parece que ya veo a dónde quiere ir usted a parar. Pero antes permítame una cuestión: ¿por qué insistir desde el principio con el "debo" y el «tengo que»? ¿No había otro filósofo que decía algo así como, "lo primero que a uno se le ocurre ante un principio ético como 'tú debes', es 'iy qué si no lo hago?»”

-Esto creo que de era Wittgenstein. Ahora comentamos esa cuestión, si le parece; pero en mi argumento empleaba esos conceptos más bien en su significado lógico: si aceptas ciertas premisas, debes aceptar sus consecuencias. Esta idea de deber es imprescindible cuando pensamos en nuestra actividad como razonadores: no podemos hacer algo como "razonar» sin asumir la necesidad de aceptar las consecuencias de nuestros razonamientos. Es una necesidad lógica, insisto, no moral: si no lo asumimos, entonces lo que estamos haciendo no es "razonan", sino, como mucho, un simulacro de razonamiento.

- Lo cierto es que ni siquiera estoy muy seguro de que "debamos" aceptar las leyes de la lógica (¿no las aceptamos porque queremos?), pero eso lo podemos discutir luego. Volviendo a las máximas, creo que lo que usted quiere decir es que una máxima sería algo así como una primera premisa (tal vez relativa a cierto ámbito de decisiones) a partir de la cual puedo ir infiriendo otras «reglas prácticas».

-Efectivamente.

-Pero esas premisas iniciales - continuó Juan - por lo general no llegamos a formularlas explícitamente en nuestros razonamientos prácticos: casi siempre nos conformamos con reglas muy particulares, y adaptadas a la situación que nos 
preocupe en cada momento. Al fin y al cabo, hizo falta nada menos que Aristóteles para formular explícitamente una teoría sobre cuál puede ser la primera premisa, o una de ellas (la búsqueda de la felicidad). Mi opinión, más modesta, es que la racionalidad sólo exige que esas reglas particulares estén organizadas en cada persona como si su objetivo último fuera alcanzar la mayor satisfacción posible de sus preferencias; tampoco es necesario que el individuo sea capaz de justificar verbalmente el por qué de cada una de sus reglas prácticas.

-Bueno - apunté-, creo que la idea de que nuestras máximas son a menudo meramente tácitas no le habría molestado a Kant. Como en el caso de Aristóteles, Epicuro y él mismo, ahí están los filósofos para hacernos explícito lo que nosotros dejamos implícito.

- Sí, pero ese carácter tácito de las reglas deja abiertos muchos problemas —protestó-. Por ejemplo, ¿̨cada persona tiene una sola máxima, o puede seguir varias a la vez, quizá para ámbitos distintos de la vida? ¿Pueden personas diferentes tener máximas generales distintas? ¿Pueden ser contradictorias entre sí las máximas que sigue una misma persona? ¿Pueden ser mis razonamientos de tal manera que no se pueda encontrar, ni explícita ni implícitamente, una primera premisa que los justifique? ¿Habrá "primeras premisas» con contenido puramente práctico, por un lado, y "primeras premisas" con contenido puramente fáctico, por otro (al fin y al cabo, para justificar lo de la lluvia y el paraguas también tengo que utilizar la premisa "porque la lluvia moja»)? Si esto es así, ¿las "leyes de la naturaleza» deberán también ser tomadas como "máximas", al menos en la medida en que yo tenga que tenerlas en cuenta para justificar las conclusiones prácticas de mis razonamientos? ¿Estarán irremisiblemente mezclados en todas las «máximas» los contenidos fácticos y los pragmáticos? Y lo más importante, ¿cómo aprende uno esas máximas?, ¿las "copia" de otras personas?, ¿las halla por experiencia o son a priori?, y en definitiva, ¿por qué sigue unas máximas en vez de otras?

Juan López dejó esta pregunta en el aire. Yo tardé unos segundos en reaccionar.

—No sabría que decirle - musité al cabo-. ¿Qué piensa usted?

-Bueno, mi problema es que no sé como respondería Kant a esas cuestiones, ni siquiera si las consideraría legítimas; las respuestas son para mí tan complicadas, 
y en cambio tan obvias las preguntas, que me extraña muchísimo que Kant no las plantee siquiera. ¡ $Y$ eso me hace pensar que él estaba entendiendo la cuestión de las "máximas» de una forma totalmente distinta a la que yo me imagino, y que (si me permite la descortesía) no sé si coincide con lo que usted me intenta explicar! Por ejemplo, muchas de las máximas que él menciona (cosas como "mentiré cuando me venga bien») no son tan generales como sugiere el argumento de usted. Así que no sé si en realidad estoy entendiendo lo que Kant quiere decir.

- Pero qué piensa usted - ya me iba atreviendo a preguntar al homo oeconomicus, o lo que fuera, sus propias opiniones.

-Primero le explicaré más despacio algunas de las dificultades que tengo con la noción kantiana de «máxima». Por ejemplo, en cada máxima debe estar recogida una cierta descripción, o conceptualización, de la situación a la que ha de aplicarse. Según Kant, pienso, y por lo que parece, también según usted, cada uno nosotros iría por la vida con un puñado de reglas que dicen «en tales y cuales circunstancias, hágase esto». Pues bien, la situación real en la que alguien efectivamente se encuentra puede siempre describirse de miles de maneras distintas, dependiendo, en parte (pero sólo en parte), del detalle con el que queramos describirla, y también dependiendo del vocabulario que utilicemos. Además, nunca hay dos situaciones que sean exactamente iguales en todo. Así pues, en principio es posible que yo tuviera una máxima específica para cada situación posible. Piense en un ejemplo de los que pone Kant -rebuscó en el libro-: "cuando me crea estar apurado de dinero, tomaré a préstamo y prometeré el pago, aun cuando sé que no lo voy a verificar nunca». ¿ Por qué la condición es "estar apurado de dinero"? ¿Por qué no «estar apurado de dinero por tales y cuales razones" (que nunca son exactamente las mismas), o "en tal o cual cantidad"? ¿Y por qué "tomaré a préstamo", en vez de "le pediré prestado a Fulanito" (o, si no quiere usted nombres propios, «le pediré a alguien con tales y cuales características")? Llevado hasta sus últimas consecuencias, esto vacía de sentido el argumento de Kant acerca de qué máximas son correctas moralmente (recuerde: las que uno puede querer que las siga todo el mundo siempre), pues si cada máxima sólo se puede cumplir en un caso (es decir, si se refiere a una situación definida con todo el detalle posible), entonces todas las máximas son «universalizables": pues yo siempre podré querer que cualquier persona que estuviera exactamente en la misma situación que yo, se comportara exactamente como yo quiero hacer. No tengo ningún riesgo al hacerlo así: al fin y al cabo, nunca nadie volverá a estar en esa situación «exactamente». 
- Creo que eso sólo indica que las verdaderas "máximas" deben ser mucho más generales, y poderse aplicar a muchos casos posibles. Al fin y al cabo, ocurre con ellas como con cualquier concepto (no hay conceptos para un solo caso posi$b l e$ ). Le admito que tal vez no tengan por qué ser la urazón última» de cualquier decisión que uno tome, pero me sigue pareciendo pertinente la idea de que una máxima es una regla que alguien usa para justificar por qué sigue determinadas reglas... Aunque, en fin, puede que con esta opinión esté yendo más allá de lo que el propio Kant sugiere. Y, por otro lado, una crítica parecida podría hacérsele a la teoría que usted defiende sobre la racionalidad: si cada situación es absolutamente independiente de las demás (por ejemplo, si alguien puede preferir $\mathrm{X}$ a $Y$ en una situación, e Y a X en otra situación que es sólo imperceptiblemente distinta de la primera), entonces cualquier acción sería racional, aunque la conducta del individuo pareciese bastante caótica.

- Reconozco que, para que la racionalidad de la elección tenga sentido, las preferencias deben estar definidas con un grado bastante alto de generalidad. Tal vez la solución a este problema esté conectada con la solución que demos a la dificultad sobre las máximas kantianas. Tendré que pensarlo — sentenció Juan, anotando unos garabatos en alguna página del libro.

-Volviendo a las preguntas que planteaba usted hace poco —dije yo entretanto-, ¿cree que alguien podría seguir máximas contradictorias, por ejemplo?

Juan soltó el libro y el bolígrafo, y empezó entonces a sorber el café, que no había tocado desde que el camarero lo sirvió.

- Primero, parece claro que alguien puede intentar seguir máximas mutuamente contradictorias, al menos mientras no se da cuenta de que lo son (y tal vez incluso después). Pero si es un individuo racional, tarde o temprano percibirá el error y lo corregirá, o bien sus propios fracasos, o la competencia con otros individuos, terminarán por ponerlo fuera de juego, y ya no tendrá que tomar decisiones en las que intervengan las máximas conflictivas. De todas formas, déjeme insistir en que la idea de que "tomamos decisiones siguiendo reglas" me parece bastante sospechosa; lo veo como una contradicción en los términos: al fin y al cabo, usamos las reglas para no tener que tomar demasiadas decisiones, y tenemos que tomar decisiones precisamente cuando las reglas no nos ayudan. Tomar decisiones es una cuestión de sopesar los pros y los contras, de calcular la utilidad que me reportará cada alternativa, si me permite expresarlo así. No es una cuestión de aplicar reglas mecánicamente. 
- ¿Pero no hay algo contradictorio también en la idea de que alguien toma una decisión «racional» sin seguir reglas de ningún tipo? -interrumpí- ¿No sería esa decisión totalmente arbitraria y caótica, sin garantía alguna de éxito? En definitiva, ¡cómo puede uno calcular sin seguir al menos las reglas del algún cálculo, determinadas reglas de inferencia? -esto me hizo darme cuenta de una nueva cuestión-: Al fin y al cabo, para que la decisión sea racional, ese cálculo debe estar «bien» hecho, es decir, debe haberse llevado a cabo siguiendo las reglas "adecuadas". ¿Será lo definitorio de los agentes racionales, entonces, no sólo que puedan seguir reglas en sus razonamientos, sino sobre todo el que sean capaces de discernir las reglas "correctas»?

- "Correcto" y «adecuado" siempre significa para mí "coherente con la máxima satisfacción de las preferencias del individuo". Le veo a usted demasiado preocupado con los procedimientos mediante los cuales llega una persona a alcanzar sus decisiones. Tal vez el mismo Kant también lo estaba, aunque, si así era, hay que reconocer que expresaba su preocupación en un lenguaje que a menudo me resulta difícil asociar exactamente a ese tipo de preguntas. Pero mi punto de vista, y lo que me hace más difícil entender las tesis kantianas, es precisamente que lo importante es el resultado, más que el procedimiento. Mire, la evolución biológica, y posiblemente la evolución cultural, nos han proporcionado mecanismos que nos ayudan a eliminar nuestros errores; cuáles sean esos mecanismos es algo que, desde el punto de vista práctico, importa poco, y desde el punto de vista científico... ¡vaya, no es algo que podamos averiguar meramente reflexionando!

- ¿Y cómo puede usted tener tanta confianza en que de hecho esos mecanismos eliminan nuestros errores siempre, o al menos un número "suficiente" de veces? Tal vez no sea así. Como acaba usted de decir: es una cuestión empírica.

-Bueno, no estaríamos aquí si cometiéramos errores demasiado a menudo, sobre todo cuando la competencia es feroz, como en los ámbitos de la economía, de la política, o de la ciencia.

Eché un vistazo a la concurrencia del macabro garito. Las miradas de algunos parroquianos me hacían sentir de arriba abajo un contrajemplo a lo que mi interlocutor acababa de afirmar. Me pareció que nuestra presencia allí era uno de esos errores que nos quitarían súbitamente de en medio a Juan López y a mí con un zarpazo ensangrentado, por haber sido tan estú- 
pidos como para meternos en aquel tugurio a esas horas de la noche. Pero no quise darle más vueltas al tema. Al fin y al cabo, eso sería tomarle a Juan por alguien tan imbécil como yo mismo, y la cortesía estaba antes que nada.

-Supongo -pregunté al cabo de unos instantes- que, por decirlo en términos kantianos, usted se guiará por la máxima de elegir siempre la opción que maximiza su función de utilidad, ¿no?

-Ya le digo que no me convence mucho esa forma de hablar (la de las «máximas"), pero, como parece que no vamos a llegar a un acuerdo sobre ello, pongámoslo de esa manera si prefiere usted verlo así. Hay que tener en cuenta antes que nada que la "función de utilidad" es nada más que una representación numérica del orden (y, en la medida de lo posible, de la intensidad) de las preferencias, que son las que en último término cuentan; no es que vaya yo por ahí echando números para decidir qué película voy a ver, o qué consumición pido en el bar. Por cierto, ya se ha acabado usted la suya, y yo también mi café. ¿Quiere otra cosa?

- Más de lo mismo - dije, levantando mi vasito vacío. Juan fue esta vez quien se volvió para avisar al camarero y pedirle una nueva ronda.

-Y entonces, volviendo al tema de la ética —continué-, ¿le parece a usted que esa máxima, la de perseguir siempre el propio interés, sería universalizable? ¿Podríamos querer que todo el mundo la siguiera siempre?

-Eso depende, no creo que se pueda dar una respuesta general. Bajo ciertas circunstancias, el que cada uno vaya por ahí intentando obtener el mayor beneficio posible produce un resultado colectivo que es mejor para cada uno que lo que sería si dejáramos que un dictádor estableciese unas normas fijas que todos deberían seguir, por muy benévolo que ese dictador fuese. Esto se debe sobre todo un problema de información y de incentivos: el dictador no sabría bien qué cosas prefiere cada uno, y los individuos tampoco estarían muy dispuestos a facilitarle las cosas si ven que pueden perder algo una vez sean impuestas las reglas, o ganar algo no cumpliéndolas.

-Pero esto no es así en muchas otras circunstancias, que no son el mercado libremente competitivo al que se referirá seguramente usted en el ejemplo que acaba de poner. Piense en un caso (¡que los hay a miles!) que tenga la estructura del dilema del prisionero... Si me permite una servilleta. 
Juan extrajo una del dispensador, la desdobló y me la acercó. Desenfudé el bolígrafo y empecé a dibujar.

\section{PEPE}

A

B

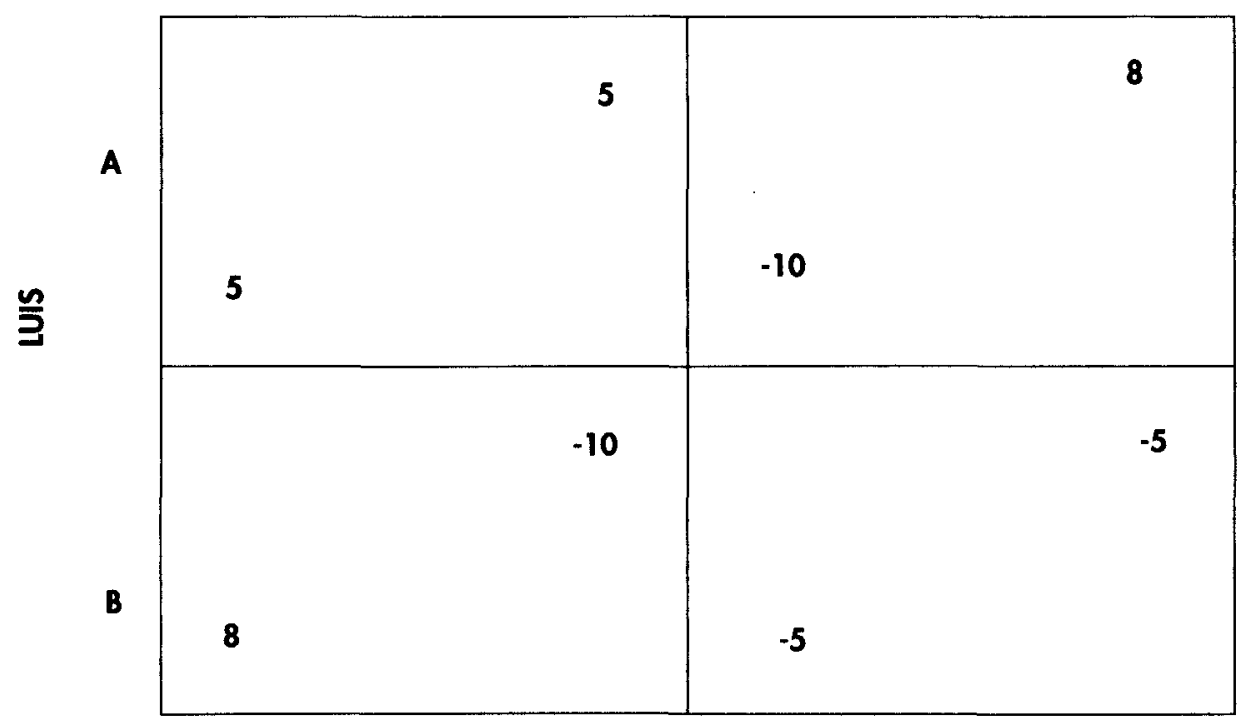

\section{Servilleta 1}

-Estoy seguro de que conoce usted perfectamente esto tan trivial -me disculpé-, pero me será útil para mi argumento. Estos dos individuos, Pepe y Luis, pueden elegir cada uno de ellos dos opciones, A y B, y obtendrán las ganancias o pérdidas que pone en la casilla correspondiente, ¿vale? Supongamos ahora que cada uno sigue la máxima de "tomar aquella decisión que maximiza mi función de utilidad"; en ese caso, ambos elegirán la opción $B$, pues, por ejemplo, Luis preferirá esta opción elija lo que elija su compañero: si Pepe elige A, Luis ganará 8 maravedíes eligiendo $\mathrm{B}$, pero sólo 5 eligiendo $\mathrm{A}$, y si Pepe elige $\mathrm{B}$, Luis perderá 10 eligiendo $\mathrm{A}, \mathrm{y}$ sólo perderá 5 eligiendo $\mathrm{B}$. La situación para Pepe es idéntica. Así que, si ambos persiguen maximizar su utilidad, perderán 5 cada uno, mientras que si hubieran elegido A los dos, habrían ganado 5.

«Esto quiere decir - continué, dejando el bolígrafo sobre la mesa con gesto triunfante- que Pepe y Luis preferirían una situación en la que ninguno de ellos 
sigue la máxima favorita de usted, en vez de la situación en la que la siguieran ambos. Luego la máxima no es «universalizable». De hecho, cada uno de ellos preferiría que el otro no la siguiera, y eligiese la opción $\mathrm{A}$, dándole así a él la oportunidad de ganar 8 ...

Juan hacía tiempo que parecía ignorar lo que estaba contándole, como si fuese una aburrida historia mil veces escuchada.

-No insista, no insista -me dijo-. En realidad, yo no afirmo que la máxima de la maximización sea «universalizable» en el sentido de Kant; $y$ no creo que eso tenga ninguna repercusión. Además, ya le reconocí hace un momento que la máxima de elegir la opción más preferible conduce a un resultado mejor para todos en algunas circunstancias. Eso no quiere decir que sea siempre lo mejor; pero sí que quiere decir, me parece, que la máxima de «seguir unas reglas de conducta establecidas como obligatorias" tampoco garantiza un resultado óptimo en todos los casos. O sea, que es posible que existan circunstancias en las que un grupo de individuos que obedecen un «imperativo categórico" salgan todos ellos peor parados que otro grupo en el que cada uno hace lo que le da la gana. Si esto es así, hay casos en los que individuos racionales no podrian desear que "todos" obedecieran siempre el imperativo categórico. Luego este imperativo tampoco es «universalizable», como dicen Kant y usted.

-No lo veo muy claro... Creo que el ejemplo en el que está usted pensando es el de un «mercado libre» frente a una "economía dirigida», ¿no es así?

-Es un ejemplo, sí, aunque no necesariamente el único.

-Pues bien, en ese caso, las «normias» que establecería un "dictador (benevolente)" no serían equiparables sin más a un «imperativo categóricom; son simplemente normas que deben cumplirse bajo la amenaza de los castigos, pero ipor qué tendría que pensar cada ciudadano de una economía dirigida que tiene el deber moral de cumplir esas reglas, en vez de otras? Es decir, no creo que su interpretación suponga realmente un problema para la noción kantiana del deber.

-Dejemos de momento la cuestión del deber para más tarde, pues, por lo que he visto hasta ahora, es un concepto que entiendo menos cuanto más lo pienso. Lo que le sugiero es, más bien, que imaginemos que los propios ciudadanos (más que un único «dictador») se reúnen para intentar decidir cuáles son 
las leyes que harían que la economía (o cualquier otro ámbito de la sociedad) "funcionara» lo mejor posible, es decir, de la manera más satisfactoria según sus propias preferencias; y esas leyes son las que "deberían" cumplir. Mi tesis es que, en muchos casos, a esos ciudadanos les iría peor si intentaran hacerlo así, es decir, si intentaran guiarse por el «deber", que si cada cual hace simplemente lo que le da la gana.

-Bueno, si eso es así, puede ser por dos razones distintas: bien porque antes de decidir qué leyes aplicar, algunos no revelan toda la información necesaria sobre sus preferencias o sus posibilidades, o votan por una ley que no es la que realmente piensan que es mejor, o bien porque después de elegir las leyes, la gente no las cumpla. Ahora bien, en ambos casos podemos decir que la razón por la que la sociedad (o uno de sus ámbitos) funciona peor bajo el imperio de las normas que bajo un sistema de libertad absoluta, es porque la gente no hace realmente lo que debe. Dicho de otra manera, lo que usted afirma es que "(en ciertas circunstancias) si la gente cumpliera con su deber, estarían peor que si hicieran lo que quisiesen, porque en realidad no llegarian a cumplir con su debern. Ya, pero la cuestión es: ¿y si cumplieran?

Juan sonrió.

- La primera de sus razones, ¿no indica más bien que la gente no sería capaz de ponerse de acuerdo, públicamente al menos, en cuál es su deber? Y la segunda, ¿no nos sugiere que, si uno espera que los demás no cumplirán con su deber, entonces también a él le irá mejor haciendo lo que le venga en gana? Fijese de nuevo en su ejemplito de la servilleta; imagínese que Pepe está seguro de que Luis, pese a todas las cavilaciones morales y apretones de manos, va a decidirse por la opción B (la "egoísta", como tal vez diría usted); en ese caso, las dos opciones de Pepe son, o bien elegir A y perder con ello 10, o bien elegir B y perder sólo 5. ¿No era Sócrates el que decía que era mejor sufrir una injusticia que cometerla? Pues en nuestro ejemplo, Sócrates se equivoca de cabo a rabo, porque, si tuviera razón, los números escritos en las casillas no representarían correctamente las preferencias de los individuos: para el Pepe de la servilleta, perder 10 ("sufrir la injusticia») es indudablemente peor que perder 5 ("cometerla»).

- Pero - protesté ruidosamente, golpeando la mesa con el culo de mi vaso vacío; creo que debí llamar la antención de los parroquianos, pero mi argumento me absorbía demasiado como para fijarme en el resto del tugurio-, ¿no ve 
que su teoría de la racionalidad condena... - y lo repetí levantando imprudentemente el vaso y la voz- ; condena! a Luis y a Pepe a obtener un resultado desastroso precisamente por estar empeñados en obtener cada uno por su cuenta el máximo beneficio posible? ¿Es que no les llega la razón para inventarse alguna forma de alcanzar la primera casilla?

- iClaro que les llega! Pero no por el camino que usted y Kant parecen desear (el de modificar los criterios que los individuos utilizan para tomar sus decisiones), sino cambiando efectivamente la situación para convertirla en un juego distinto, en el cual el resultado de la búsqueda del propio beneficio por parte de cada individuo sea una casilla aceptablemente buena para todos. Así es como los seres humanos reales "resuelven" las situaciones como el "dilema del prisionero": deshaciéndolas y transformándolas en otras. Pero si de hecho se encuentran en un juego como el del prisionero, lo racional será elegir la opción "egoísta».

- i mí me parece obvio que lo "racional" sería que ambos eligieran la opción A! ¡Deberian poder ponerse de acuerdo en ello!

-Pero, si yo sé que el otro va a elegir A, lo racional para mi será elegir B en ese caso. Al fin y al cabo, en ese caso ganaré 8 en lugar de cinco.

—Y $Y$ el otro perderá 10, en vez de ganar 5 !

Juan miró discretamente a nuestro alrededor, y me sugirió por señas que bajara la voz: la mayor parte de los parroquianos estaban mirándonos con cara no sé si de sorpresa o de molestia, y sería mejor no intentar averiguarlo.

- Vaya - dijo al fin-, veo que usted comete uno de los grandes errores de quienes intentan analizar la teoría de juegos desde el punto de vista normativo.

—¿Un error? ¿Qué error?

- Pues el de pensar que, además de preocuparse por sus propios niveles de utilidad, cada individuo debe preocuparse «de alguna manera" por la utilidad que obtienen los demás.

- iEs un principio moral básico, si a usted no le importa! ¡Al fin y al cabo, en eso consiste "tomar a los demás como un fin, y no como un medion! - -visto 
en retrospectiva, creo que los carajillos me iban haciendo tomar partido por Kant cada vez con más fuerza-. Por cierto - añadí, mirando desolado nuestros vasos vacíos-, ¿quiere otro café?, ¿o alguna otra cosa? Desde que llevo aquí no ha tomado usted ni una copa. ¡ Venga, anímese! No veo motivo para que el homo oeconomicus tenga que ser abstemio.

Juan me miró como pensando que tal vez era yo quien debía pasarse a alguna bebida sin alcohol, pero no dijo nada sobre ello. Pidió un brandy, y yo le acompañé, aunque le prometí que sería la última. El mesonero trajo las dos copas y una botella de 103. Juan tomó su copa en la mano sin llevarla a la boca mientras yo daba cuenta de buena parte de la mía. Estaba en ello cuando él siguió diciendo:

-Le explicaba que es un error decir que un individuo, en un juego, va a preocuparse por los niveles de utilidad de los demás una vez que están dados sus propios niveles de utilidad. Pensar tal cosa siginifica que uno no ha entenido lo que representa la función de utilidad. Por ejemplo, en las cuatro casillas dibujadas en la servilleta, cada número quiere decir qué grado de satisfacción obtiene el jugador correspondiente teniendo en cuenta todas las consecuencias de las decisiones (previsibles) que se han tomado para llegar a esa casilla, incluyendo el hecho de que el otro jugador vaya a obtener la utilidad indicada en esa casilla. Así, en las dos casillas de arriba, el hecho de que Pepe obtenga 5 en la izquierda y 8 en la derecha, no significa necesariamente que obtenga 5 y 8 maravedíes y eso sea lo único que le importa, sino que, sea lo que sea lo que suceda si la situación a la que se llega es la que representan esos cuadros, Pepe prefiere el cuadro de la derecha al de la izquierda (en una proporción de 8 a 5 , aunque los números podrían cambiar). Y, lo más importante, cuando digo que lo "prefiere", lo único que quiero decir es que, al optar entre ambas posibilidades, elegirá la derecha, y no entro a buscar ninguna explicación acerca de por qué lo hará.

—O sea, que son sólo «preferencias reveladas».

-Así es. Se trata de algo que casi siempre se olvida al pensar en los juegos, y mira que lo hemos explicado veces. En realidad, en la representación habitual de un juego se están mezclando dos cosas distintas, que hay que saber separar. Por un lado está el resultado, la situación a la que se llega cuando cada jugador toma una determinada decisión - Juan tomó otra servilleta y fue dibujando-; en el juego que usted ha puesto como ejemplo antes, podría ser así. Por otro 
lado, está el nivel de satisfacción de las preferencias que cada jugador alcanzaría si se cumpliese dicha situación. ¿Ve?

\section{PEPE}

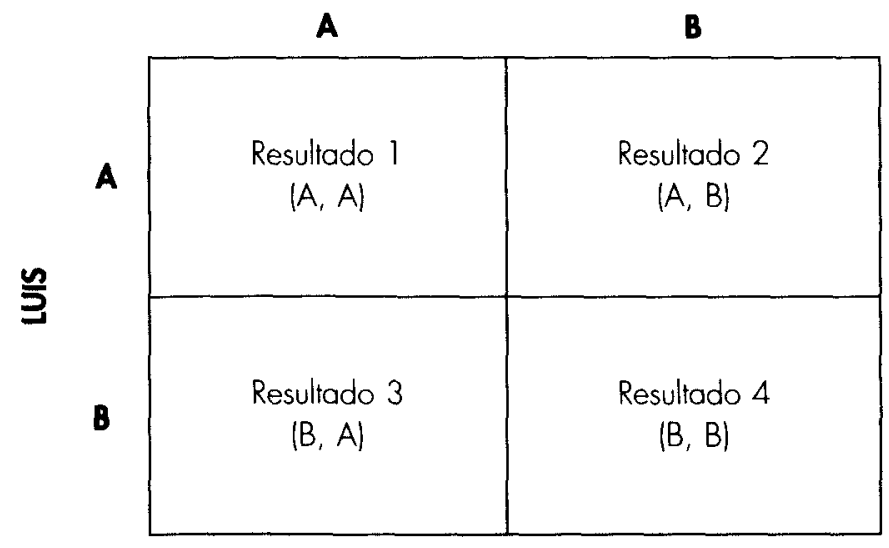

Servilleta 2

\section{UTIUDADES}

$\begin{array}{ccc}\text { RESULTADO } & \text { LUIS } & \text { PEPE } \\ & & \\ 1(A, A) & 5 & 5 \\ 2(A, B) & -10 & 8 \\ 3(B, A) & 8 & -10 \\ 4(B, B,) & -5 & -5\end{array}$

Al terminar de dibujar, dio la vuelta a la servilleta para mostrármela, y luego tomó de nuevo la primera, escribiendo algo en ella, e indicando con el bolígrafo algunos de los números.

-Para que lo vea usted todavía más claro. Imagínese que Pepe y Luis son dos sujetos absolutamente kantianos, por así decir, preocupados únicamente por cumplir con su deber, pero que, para su desgracia, no tienen la misma opinión acerca de cuál es su deber.

-Eso sería muy poco kantiano — protesté-; el deber es universal, dígalo Agamenón o su porquero. 
-Pero yo soy como el porquero: esa universalidad no me convence. Suponga que se trata de los gobernantes de dos países vecinos, que discuten sobre el aborto, o sobre la clonación humana. A y B pueden ser dos medidas políticas relacionadas con uno de esos temas: en el caso de Luis, que es radicalmente (es decir, kantianamente) proabortista, la decisión A sería prohibir el aborto en su país, y B permitirlo; en el caso de Pepe, que es radicalmente antiabortista, A consistiría en no castigar a las mujeres de su país que vayan a abortar al otro país, y $\mathrm{B}$ consistiría en castigarlas de forma terriblemente severa, mucho más severa que cuando son castigadas en el otro país; tan severa, de hecho, que Luis experimentará un gran sufrimiento por ellas. (Note usted que A y B no son, en este ejemplo, la misma acción para Pepe que para Luis; pero eso no es esencial para que el juego sea un «dilema del prisionero»).

"Para simplificar la situación, imagine también que en el pais de Luis el nivel de educación sexual es tan elevado que ninguna mujer se queda embarazada sin desearlo, de forma que allí sólo acuden a abortar mujeres del otro país. En cambio, aunque el aborto esté prohibido en ambos países, algunos casos ocurrirán (tal vez muchos), y ambos gobiernos tendrán que castigarlos si se descubren. Por último, supongamos que no todas las mujeres que abortan en el país de Luis son descubiertas por el gobierno del país de Pepe.

PEPE

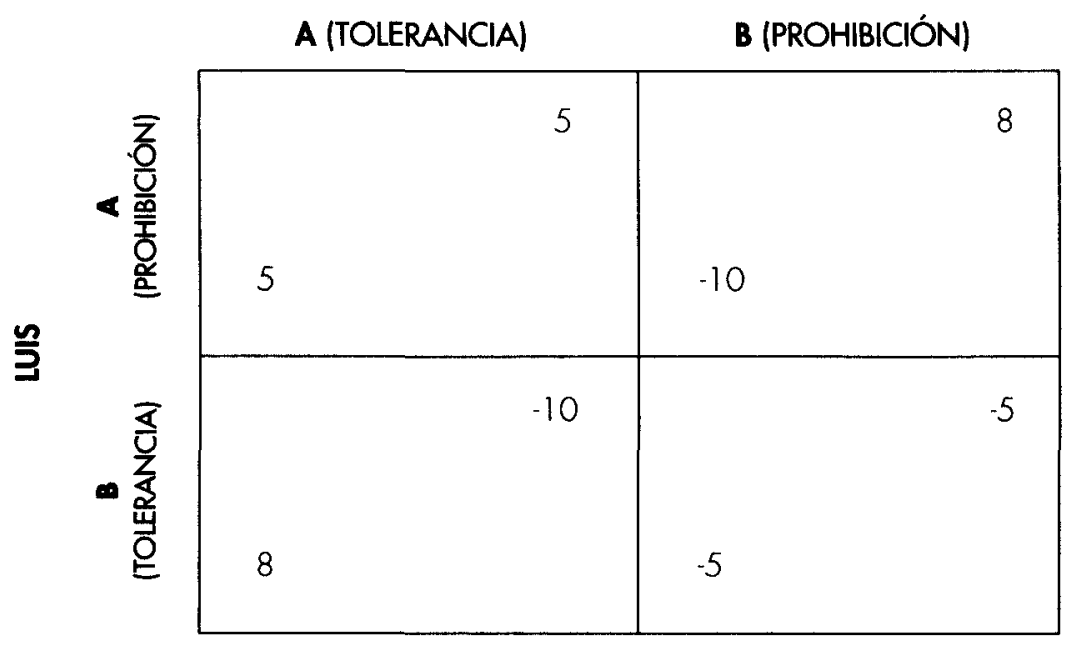

Servilleta 3 (o sea: la servilleta 1 con añadidos). 
"La situación es entonces un "dilema del prisionero" perfecto. Veamos cada casilla. La de arriba a la derecha (prohibición en ambos países) es muy mala para Luis, porque no aplica la política proabortista que desearía, tiene que sufrir por el castigo que él mismo impone a las mujeres que abortan y a los médicos que las ayudan, $y$ además tiene que soportar que el gobierno de Pepe imponga también sus terribles castigos. En cambio, la situación es la mejor posible para Pepe, que ve cómo el aborto se prohibe en ambos países, y además encuentra una íntima satisfacción en ver cómo son castigadas algunas de las mujeres que han abortado.

«La casilla de abajo a la izquierda (tolerancia en ambos países) es la peor para Pepe, quien ve cómo las mujeres de su país abortan, sin ser castigadas en ninguno de los dos países, pero es la mejor para Luis, que ve satisfechos sus principios proabortistas.

«Finalmente, la casilla de abajo a la derecha (tolerancia en el país abortista, y prohibición - muy severa, recuerde - en el antiabortista) es mejor para Pepe que la casilla de abajo a la izquierda (tolerancia en ambos países). También es mejor para Luis que la casilla de arriba a la derecha (prohibición en ambos países). ;Pero es peor para ambos que la casilla de arriba a la izquierda! Esa primera casilla $(A, A)$ es mejor para Luis que la última $(B, B)$ porque los castigos que sufren las mujeres que abortan son muchísimo menos severos, ya que los aplica su país, y no el de Pepe; y es mejor para Pepe porque abortan muchas menos mujeres en total, ya que, al fin y al cabo, en el país de Luis el aborto está prohibido en la casilla $(A, A)$, mientras que en la casilla $(B, B)$ está permitido.

"Así pues, incluso suponiendo que las preferencias de los individuos estén influidas exclusivamente por consideraciones morales, pueden darse situaciones como el "dilema del prisionero", y por lo tanto, no será la moral la que permita resolver dichas situaciones.

Ante tan larga parrafada (si bien para facilidad y alivio del sufrido lector yo he repartido aquí en varios párrafos lo que en definitiva no los tenía, pues se trataba de lenguaje oral, y con muy pocas pausas), no supe bien cómo reaccionar en un principio (en parte porque los puntos y aparte los había ido marcando yo de manera más o menos virtual con los tragos con los que fui apurando mi copa), y me quedé un rato señalando con el dedo índice ora a unos numeritos, ora a los otros. Finalmente el índice volvió a la punta de mi nariz. 
-Bueno, bueno. Todo su argumento depende de la suposición de que puede haber varias personas que siguen una moral «kantiana» en abstracto, aunque en la práctica sus argumentos les lleven a aceptar normas morales concretas que sean diferentes de las de los otros.

-Efectivamente, pero, si no está usted de acuerdo con esto, podemos intentar encontrar un kantiano abortista y otro antiabortista. Yo apuesto a que los hallaremos.

—Seguro que sí. La cuestión es si ambos serán auténticos kantianos.

- ¿Y cómo averiguar cuál de los dos es el «auténtico? No me parece que esa discusión nos pudiera llevar demasiado lejos.

-Entonces, volviendo a lo de antes — dije-, la moral estará inscrita, si me permite expresarlo así, en la función de utilidad de los individuos. Habrá algunas personas en cuyas preferencias sea tenida en cuenta la situación de las demás, y otras personas en las que no. Pero, ¿no podemos decir que uno debe tener en cuenta el bienestar de los demás, aunque no tenga un interés especial por ellos en sus propias preferencias? ¿Cómo representaría usted la obligación moral de «tomar a los demás como un fin en sí mismo»?

-Ya le dije antes que, auque he ido utilizando el concepto porque imaginaba que así me entendería usted, yo mismo no tengo nada claro, en el fondo, qué quiere decir Kant con eso del «deber». Respecto a los «imperativos hipotéticosn, como él los llama, la respuesta parece más o menos sencilla: si tengo ante mí ciertas opciones, que valoro según sus posibles efectos, elegiré aquella cuyas consecuencias sean preferibles para mí; pero esa opción, ila llevo a cabo porque "debo hacerlo si quiero obtener aquellas consecuencias", o más bien por que es la opción que, simplemente, quiero realizar? No creo que haya diferencia entre ambas formas de hablar, de modo que el primer "debo" es totalmente superfluo.

-No, no. No es tan superfluo - dije- Imagine que puedo elegir entre $X \mathrm{e}$ $\mathrm{Y}$, que $\mathrm{X}$ me permite obtener $\mathrm{Z}$, e $\mathrm{Y}$ me conduce a W. Puede que yo prefiera $\mathrm{Z}$ a $\mathrm{W}$, y en ese caso haré $\mathrm{X}$ si $X$ misma no es más desagradable de hacer que $\mathrm{Y}$. Es decir, mis preferencias no deben estar definidas sólo sobre $\mathrm{Z}$ y W (las «consecuencias"), sino también sobre mis actos. Sólo diré que debo hacer X si prefiero $Y$ a X. Si prefiriese $\mathrm{X}$ a $\mathrm{Y}$, entonces no diría que hago $\mathrm{X}$ "porque debo hacerlo para conseguir

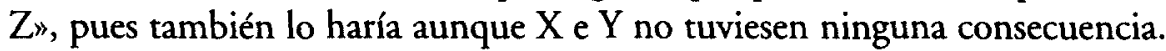


-Me parece muy oportuna su idea. Es más, es una lástima que yo esté jubilado ya, pues podría habérsela comentado a algunos que han utilizado mis opiniones para discutir sobre asuntos morales. Pero, como usted supondrá, el problema delicado es el del imperativo categórico. ¿Qué quiere decir que yo deba hacer una cosa, independientemente de qué sea lo que yo prefiera? Tal como yo lo veo, la única forma de interpretar esta frase es de la manera siguiente:

"Mis preferencias sobre ciertas opciones dependen de un cierto número de propiedades de esas opciones. Por ejemplo, mis preferencias sobre las viviendas dependen de la situación de cada una, su tamaño, y otras muchas cualidades; puedo elegir una vivienda que tenga alguna característica peor que otra que no he elegido (digamos, no es la más grande de todas, ni la más barata), pero, teniendo en cuenta todas sus cualidades, prefiero la primera. Con respecto a las acciones, también las valoro según muchos criterios: lo cómodo que me resulta llevarlas a cabo, el gusto que me dan algunas de sus consecuencias, lo mal visto que seré por los demás si las hago, etc.; y entre esos criterios está el de lo moralmente correcta que me parece cada una de ellas. Como en el caso de las viviendas, yo puedo realizar una acción que no es la más valorada por mí según algunos de esos criterios (jentre ellos, la obligación moral!), pero que sea la que prefiero cuando los tengo en cuenta todos a la vez.

-O sea, ¡que la moral sería para usted sólo un "criterio de gusto" entre muchos otros! ¡Pues vaya una moral! — definitivamente, los carajillos y el brandy me habían terminado por convertir al kantianismo, un kantianismo en retirada, por otra parte.

- Por lo que se refiere a las decisiones de los individuos, creo que sí —respondió Juan.

- iPero Kant diría que uno siempre debe tomar aquella decisión que, según los criterios morales adecuados (ya sabe, la universalización de las máximas), es la mejor, independientemente de los demás criterios!

-Bueno, para mí ese "debe" sólo quiere decir que, según el criterio moral, esa decisión es la que puntúa más alto. También otras decisiones pueden ser las más valoradas según otros criterios (la comodidad, el qué dirán, el gusto), y tampoco por eso las tomaré, si al pensar en todos los criterios a la vez resulta que prefiero otra. 
- Pero entonces, según usted, uno no debe hacer necesariamente lo que cree que debe hacer.

- No lo diga con ese aire de paradoja. Más bien se trata de que uno no preferirá necesariamente ( $y$, por tanto, no hará, si es un sujeto racional) aquello que cree que debe hacer, de igual manera que no elegirá necesariamente el plato que más le gusta, si tiene mejores razones para elegir otro. Lo que no consigo entender es por qué Kant piensa que la razón siempre me hará preferir las opciones que son mejores desde el punto de vista moral; por qué identifica, en el fondo, la racionalidad de una acción con su valor moral. Esa pregunta es la que temo que no voy a saber responder si cae en el examen. ¡Para mí está tan claro que el sentido del deber es sólo un elemento de nuestras preferencias, pero no el único...! ¿Qué piensa usted de ello?

— ¡Yo qué voy a pensar, hombre! ¡Yo qué voy a pensar! — dije, dejando caer mis manos sobre el tablero de la mesa, y mi cabeza sobre mis manos-. Si quiere, podemos seguir discutiendo otro día; llámeme a la universidad... Al fin y al cabo, poner en parangón el discurso de un hombre ebrio con los discursos de hombres serenos es de temer que no resulte equitativo.

Creo que en aquel momento me dormí. Al menos, no consigo recordar nada desde entonces hasta que, no mucho después, comprobé que me hallaba solo en la mesa. Un platillo de plástico marrón contenía los céntimos que, seguramente, Juan (si es que no lo había imaginado yo todo, intoxicado por el contenido de los carajillos) había dejado de propina al abonar nuestras consumiciones ("ya está todo pagado", me dijo el cíclope desde detrás del mostrador cuando hice el ademán de sacar mi cartera). Los otros clientes (los que quedaban) seguían a lo suyo, sin hacer mucho caso de mí, aunque me pareció que uno de ellos, con aspecto de vendedor de clínex en los semáforos, se empezó a dirigir hacia la puerta cuando yo la traspasé y volví, solitario, al oscuro frío de la noche. Suspirando, me subí el cuello del abrigo mientras rogaba al dios de los imperativos categóricos que sólo hubiera sido una casualidad. 